\title{
The role of response directedness in discriminative and conditional stimulus control
}

\author{
DAVID R. THOMAS and PATRICK J. CURRAN \\ University of Colorado, Boulder, Colorado
}

\begin{abstract}
Six pigeons were trained to press a treadle for variable-interval reinforcement when a blue light was present on the response key; a red light signaled extinction. Subsequently the birds were trained on the reversal of this discrimination. During initial training the houselight was off in the operant chamber; during reversal training it was on. The subjects learned the discrimination problems, although they performed substantially more poorly than they do when the keypeck response is used. Wavelength generalization testing in extinction with the two houselight conditions alternating in blocks of trials revealed that the houselight cues had gained conditional control over discriminative responding; the gradients peaked at (or near) the appropriate $S+$ values in each context. Thus the directedness of the response affects discriminative stimulus control but not conditional stimulus control.
\end{abstract}

In operant conditioning experiments with pigeon subjects, it is common practice to employ visual discriminative stimuli projected on the response key. Thus the discriminative cue is localized, rather than global, and it occurs at the site of, and therefore is contiguous with, the response. Additionally, the response of pecking is part of the normal feeding repertoire of the subject. All of these factors, in combination with the pigeon's excellent vision, may contribute to the high level of discriminative stimulus control typically gained by on-key discriminative cues.

A conditional stimulus is one that serves in a hierarchical relationship to discriminative cues, indicating their significance. Thus conditional stimuli are indirectly related to behavior, in comparison with discriminative stimuli, whose relation to behavior is more direct. An example of a conditional stimulus is the houselight in the operant chamber: when it is on, a vertical line on the key is S+ and a horizontal one is $\mathrm{S}-$; when it is off, the reverse is true. In this case the conditional cue is global and diffuse, but on-key conditional stimuli, such as colored lights, may also be used. Thomas, McKelvie, and Mah (1985) reported that training a vertical-horizontal discrimination in one houselight condition followed by the reversal of this discrimination in the alternative houselight context led the houselight condition to acquire conditional control over the birds' discriminative performance, whereas (in a different group of subjects) different key colors (red and blue) on which the lines were projected were ineffective as conditional cues. Perhaps stimuli at which responding is physically directed are most likely to acquire a discriminative (i.e., direct) rather than a conditional (indirect) role. In the present study we inquired whether the formation of a conditional relationship between conditional and discriminative cues would be facili-

Requests for reprints should be addressed to David R. Thomas, Department of Psychology, Campus Box 345, University of Colorado, Boulder, CO 80309. tated by the use of discriminative cues toward which responding is directed, or conversely (and more specifically), whether the use of a treadlepress response would retard the development of conditional control by houselight cues. The use of this response is interesting because it permits a separation of stimulus localization and response directedness, two factors that are generally confounded in stimulus control studies. It was expected that the directedness of the response would affect measures of discriminative control, but whether or not it would play any role in the development of conditional control was the question of primary interest.

\section{METHOD}

\section{Subjects}

The subjects were 6 experimentally naive pigeons obtained from a local supplier and maintained at $80 \%$ of their ad-lib weights. They were housed in individual cages in a colony room with a 16:8-h light:dark cycle. Light onset was at 7:00 a.m. and subjects were run daily (except on weekends) starting at 3:00 p.m.

\section{Apparatus}

The apparatus was the same as that used by Thomas, McKelvie, Ranney, and Moye (1981). Key stimuli were produced by IEE projectors (Series 0010) with No. 1820 lamps operated at 12 V. Kodak Wratten filters Nos. 75, 74, 99, 73, and 72B produced nominal peak-transmitted wavelengths of $490,538,555,576$, and $606 \mathrm{~nm}$, respectively. Responses to the key had no programmed effect and rarely occurred. A foot treadle measuring $10.5 \times 8.5 \times 9.0 \mathrm{~cm}$ with a foot pad measuring $8.5 \times$ $6.0 \mathrm{~cm}$ at a $45^{\circ}$ angle was located at the left front corner of the experimental chamber. The treadle required a force of $50 \mathrm{~g}$ to operate and had to be released before it could be operated again. A white noise generator provided masking noise. Reinforcement was $3 \mathrm{sec}$ access to the food hopper filled with mixed grain. Recording and control were accomplished with the use of a Commodore Pet Professional Computer (Model 2001) with a locally designed and constructed interface.

\section{Procedure}

All subjects were magazine trained, shaped by the method of successive approximations to press the treadle, and then placed on a variableinterval (VI) reinforcement schedule with gradually increasing interreinforcement intervals. Throughout initial training the houselight was 
off and a light of $490 \mathrm{~nm}$ (blue) illuminated the response key. After several sessions of VI 30-sec reinforcement training, Day 1 of successive discrimination training was administered, during which treadlepress responding was reinforced on a VI 30 -sec schedule during $S+$ trials and extinguished during $S-$ trials. Subjects were run daily in 60 -min sessions composed of three blocks of five $S+(490 \mathrm{~nm})$ and five $S-(606 \mathrm{~nm})$ trials (in nonsystematic order) with the houselight off. Trials were of $55 \mathrm{sec}$ duration, separated by 3 -sec blackouts. After 22 sessions of training, all of the subjects were transferred to Phase 2 of the experiment.

In Phase 2, trials and blackouts were of the same durations as in Phase 1. However, the discrimination was the reversal of that learned in Phase 1 (i.e., S+ was now $606 \mathrm{~nm}$ and $\mathrm{S}-$ was $490 \mathrm{~nm}$ ). The houselight was on throughout Phase 2, which lasted 32 sessions.

On the day after the completion of training, all subjects were tested for wavelength generalization in extinction with the two houselight contexts alternating after every two blocks of test stimuli. The five test stimuli $(490,538,555,576$, and $606 \mathrm{~nm})$ were randomized into blocks and 12 different blocks were presented to each subject, with all tests starting in the houselight-off (Context 1) condition. During testing, as during training, stimulus presentations were of $55 \mathrm{sec}$ duration separated by 5 -sec blackout periods.

\section{RESULTS AND DISCUSSION}

One subject died during the experiment and was not replaced. The data presented are from the remaining 5 subjects. On the last training session of Phase 1 the subjects achieved a mean of $84.4 \%$ of total responses to the $\mathrm{S}+$ (range $73 \%-92 \%$ ). On the last session of reversal training the subjects yielded a mean of $85.0 \%$ of total responses to $S+($ range $70 \%-98 \%$ ). In our past experiments with the keypeck response and the same blue and red keylights, essentially perfect discrimination performance was achieved from most subjects in as few as four half-hour sessions of discrimination training (see Thomas, Stengel, Sherman, \& Woodford, 1987). Thus, despite relatively extensive training, discriminative performance with the treadlepress response was much poorer and more variable than it is with the keypeck response. This is not surprising, inasmuch as the treadlepress response often occurs without the subjects' facing the key on which the discriminative cue is projected. This is, of course, impossible when the keypeck response is employed.

For each subject, a generalization gradient was calculated separately for the responding that occurred in each houselight context; the two gradients for each subject are presented in Figure 1, along with the group mean gradients. Like the training data, the generalization test data are far more variable than are data typically obtained with the keypeck response; however, it is clear that a conditional discrimination did result from these training procedures. All subjects' gradients peaked at $490 \mathrm{~nm}$, the S+ of the original problem, when obtained in the houselightoff (Context 1) condition. No gradient obtained in Context 2 did this and all but one (from Subject B3) peaked at or near the reversal $\mathrm{S}+(606 \mathrm{~nm})$ under this test condition.

It is somewhat surprising that the gradients were sharper in the Context 1 condition than in Context 2, given the fact that the subjects had not experienced Context 1 for more than a month. Indeed, one might have anticipated a difference in the opposite direction, given the finding that discriminative stimulus control decreases with the passage of time after the completion of training (see Kraemer, 1984; Thomas \& Lopez, 1962; Thomas et al., 1985). The best explanation of the differences in the slopes of the gradients is that when the houselight is off, the colored keylight illuminates the entire experimental chamber (however dimly); thus, the subjects are exposed to the key colors regardless of the direction in which they are facing. The key colors are also more saturated and appear brighter against the dark background under this context condition. These differences may also help to explain why

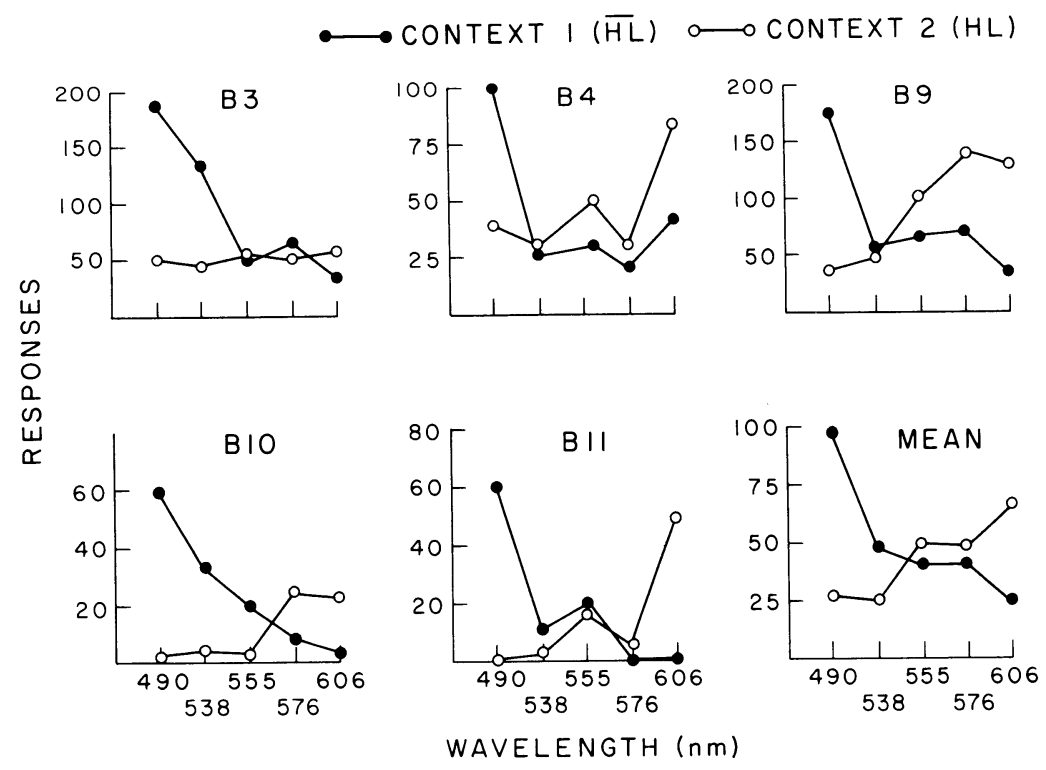

Figure 1. Individual and group average generalization gradients obtained under Context 1 (houselight off) and Context 2 (houselight on) conditions. 
more extended training (i.e., 32 sessions) was required to bring discrimination performance up to the same level in Context 2 (houselight-on) than was required in Context 1 (22 sessions), although, doubtlessly, the fact that the second problem was a reversal of the first also played a role.

Because conditional stimulus control is manifested as differences in discriminative stimulus control in the presence of different conditional stimuli, it follows that the degree of discriminative control that has been developed places a ceiling on the degree of conditional control that can be exercised. Thus we cannot directly compare the degree of conditional control revealed in keypeck and treadlepress studies when the degree of discriminative control produced is so different. However, in an unpublished study in our laboratory in which auditory discriminative cues were used and discriminative performance was comparable to that achieved here, the houselight contexts gained little or no conditional control over discrimiative performance. The finding of strong conditional control in the present experiment suggests the conclusion that although the directedness of the response dramatically affects discriminative stimulus control, there is no basis for concluding that it affects the formation of conditional relationships.

\section{REFERENCES}

KraEmer, P. J. (1984). Forgetting of visual discriminations by pigeons. Journal of Experimental Psychology: Animal Behavior Processes, 10, 530-542.

Thomas, D. R., \& Lopez, L. J. (1962). The effect of delayed testing on generalization slope. Journal of Comparative \& Physiological Psychology, 44, 541-544.

Thomas, D. R., McKelvie, A. R., \& MaH, W. L. (1985). Context as a conditional cue in operant discrimination reversal learning. Journal of Experimental Psychology: Animal Behavior Processes, 11, 317-330.

Thomas, D. R., McKelvie, A. R., Ranney, M., \& Moye, T. B. (1981). Interference in pigeons' long-term memory viewed as a retrieval problem. Animal Learning \& Behavior, 9, 581-586.

Thomas, D. R., Stengel, T., Sherman, L., \& Woodford, M. (1987). Factors affecting conditional discrimination learning by pigeons. Journal of the Experimental Analysis of Behavior, 48, 277-287.

Thomas, D. R., Windell, B. T., BakKe, I., KreYe, J., Kimose, E., \& APOSHYAN, H. (1985). Long-term memory in pigeons: I. The role of discrimination problem difficulty assessed by reacquisition measures. II. The role of stimulus modality assessed by generalization slope. Learning \& Motivation, 16, 464-477.

(Manuscript received for publication December 2, 1987.) 